\title{
Развитие системы
}

\section{поАготовки спешиалистов} по xолере

\author{
Сизова Ю.В., \\ Бурлакова О.С., \\ ヘюкшина Е.Ю., \\ Сокольская 0.A.
}

\begin{abstract}
Федеральное казенное учреждение зАравоохранения «Ростовский-на-Аону ордена Трудового Красного Знамени научно-исследовательский противочумный институт" Федеральной службы по надзору в сфере защиты прав потребителей и благополучия человека, 344002, г. Ростов-на-Аону, Российская Федерация
\end{abstract}

Угроза завоза возбудителя холеры из стран Азии и Африки сохраняет актуальность эффективной подготовки специалистов медицинских организаций и учреждений Роспотребнадзора по вопросам лабораторной диагностики и эпидемиологического надзора за данной инфекцией.

Цель - оценка развития системы подготовки специалистов по вопросам лабораторной диагностики и эпидемиологическому надзору за холерой.

Материал и методы. С использованием аналитического метода изучены законодательные, нормативно-методические документы, публикации в области подготовки специалистов для работы с возбудителями особо опасных инфекций, учебные программы профессиональной переподготовки и повышения квалификации, реализуемые на территории Российской Федерации.

Результаты и обсуждение. Система подготовки по холере изменяется в соответствии с тенденциями развития современного общества, основываясь на возрастающих требованиях к квалификации специалистов, увеличении доли самостоятельного обучения и сокращении времени учебного тематического цикла, но не позволяет полностью исключить очную форму образовательного процесса.

Заключение. Система дополнительного профессионального образования должна реагировать на потребности слушателей и осуществлять учебный процесс, используя современные информационнокоммуникационные технологии, позволяющие работающим специалистам без отрыва от производственной деятельности и в достаточно короткие сроки повышать квалификацию по вопросам лабораторной диагностики и эпидемиологическому надзору за холерой.

Конфликт интересов. Авторы заявляют об отсутствии конфликта интересов.

Финансирование. Исследование не имело спонсорской поддержки.

Вклад авторов. Концепция исследования, сбор и обработка материала - Сизова Ю.В.; написание текста - Сизова Ю.В., Бурлакова 0.С.; редактирование - Люкшина Е.Ю., Сокольская О.А.; утверждение окончательного варианта статьи - Сизова Ю.В., Бурлакова 0.C.

Для цитирования: Сизова Ю.В., Бурлакова О.С., Люкшина Е.Ю., Сокольская О.А. Развитие системы подготовки специалистов по холере // Инфекционные болезни: новости, мнения, обучение. 2020. Т. 9, № 4. С. 120-125. D0I: https://doi.org/10.33029/23053496-2020-9-4-120-125

Статья поступила в редакцию 22.04.2020. Принята в печать 09.11.2020.
Ключевые слова:

холера,

подготовка

специалистов,

непрерывное

медицинское

образование,

эпидемиологи-

ческий надзор,

повышение

квалификации

\section{Development of a system for training cholera specialists}

Sizova Yu.V., Burlakova O.S.,

Lyukshina E.Yu., Sokol'skaya O.A.
Rostov-on-Don Plague Control Researsh Institute, 344002,

Rostov-on-Don, Russian Federation

The threat of importation of the cholera pathogen from the countries of Asia and Africa remains relevant for the effective training of specialists from medical organizations and institutions of the Federal Service for Supervision of Consumer Rights Protection and Human Welfare on laboratory diagnostics and epidemiological surveillance of this infection

The aim - assessment of the development of a system for training specialists in laboratory diagnostics and epidemiological surveillance of cholera. 
Material and methods. Using the analytical method, we studied legislative, regulatory and methodological documents, publications in the field of specialist training for working with pathogens of especially dangerous infections; training programs for professional retraining and advanced training implemented in the territory of the Russian Federation.

Results. The cholera training system is changing in accordance with the development trends of modern society, based on increasing requirements for the qualifications of specialists, an increase in the share of self-study and a reduction in cycle time, but it does not completely exclude the full-time form of the educational process.

Conclusion. The system of additional professional education should respond to the needs of students and carry out the educational process using modern information and communication technologies that allow working specialists to work on-the-job and in a fairly short time to upgrade their qualifications in laboratory diagnostics and epidemiological surveillance of cholera.

Funding. The work had no sponsorship.

Conflict of interest. The authors declare no conflict of interest.

Contribution. The concept of research, the collection and processing of material - Sizova Yu.V.; writing a text - Sizova Yu.V., Burlakova 0.S.; editing - Lyukshina E.Yu,. Sokol'skaya 0.A.; approval of the final version of the article - Sizova Yu.V., Burlakova 0.S.

For citation: Sizova Yu.V., Burlakova O.S., Lyukshina E.Yu., Sokol'skaya O.A. Development of a system for training cholera specialists. Infektsionnye bolezni: novosti, mneniya, obuchenie [Infectious Diseases: News, Opinions, Training]. 2020 ; 9 (4): 120-5. DOI: https://doi.org/10.33029/2305-3496-2020-9-4-120-125 (in Russian)

Received 22.04.2020. Accepted for publication 09.11.2020.

\section{Keywords:}

cholera, specialist

training,

continuing

medical education epidemiological surveillance, increased qualification
C ложная эпидемическая обстановка по холере в ряде стран Азиатского и Африканского континентов, обусловленная экономическими, социальными и при родными факторами, наряду с интенсивным развитием международных торговых отношений и туризма, приводящим к увеличению миграции населения, значительно повышают риск завоза инфекции в Россию [1-4]. В связи с этим сохраняется актуальность систематического эпидемиологического надзора и проведения профилактических, а в случае выявления инфекции и противоэпидемических мероприятий в отношении данного заболевания, эффективность которых обеспечивается формированием высококомпетентного кадрового состава медицинских организаций (М0) и учреждений Роспотребнадзора, выполняющих свои должностные обязанности на высоком профессиональном уровне. Это напрямую связано с качеством профессионального обучения, а также с устойчивой мотивацией специалиста к регулярному пополнению знаний с учетом современных достижений медико-биологических наук в соответствии с профилем специальности для полноценной реализации в сфере профессиональной деятельности. Подготовка специалистов (врачей-эпидемиологов, врачей-бактериологов, научных сотрудников, лаборантов) учреждений Роспотребнадзора, других министерств и ведомств, участвующих в осуществлении эпидемиологического надзора за холерой, является важной задачей и способствует профессиональному реагированию на ситуации, связанные с появлением в стране возможных вспышек холеры.

Цель исследования - оценка развития системы подготовки специалистов по вопросам лабораторной диагностики и эпидемиологическому надзору за холерой.

\section{Материал и методы}

Материалами для исследования послужили законодательные, нормативно-методические документы, публикации в области подготовки специалистов для работы с возбудителями особо опасных инфекций (00И), учебные программы профессиональной переподготовки и повышения квалификации, реализуемые на территории РФ. В работе использован аналитический метод.

\section{Результаты и обсужАение}

В Российской Федерации в соответствии с действующей нормативно-методической документацией к работе с патогенными биологическими агентами (ПБА) I-II групп патогенности допускаются специалисты, имеющие базовое профессиональное образование (медицинское, биологическое, ветеринарное) и прошедшие переподготовку по программам дополнительного профессионального образования для приобретения навыков безопасной работы с возбудителями 00И [5].

В настоящее время дополнительной подготовкой специалистов по 00И занимаются противочумные учреждения (5 институтов и 14 станций) и центры гигиены и эпидемиологии в субъектах РФ.

Противочумные институты Роспотребнадзора, имеющие лицензию на образовательную деятельность, за многолетнюю практику приобрели значительный опыт подготовки высококвалифицированных кадров при реализации дополнительных профессиональных программ переподготовки и повышения квалификации специалистов учреждений Федеральной службы по надзору в сфере защиты прав потребителей и благополучия человека, организаций Министерства здравоохранения и других ведомств, работающих с ПБА I-II групп патогенности, в том числе с холерой. Повышение квалификации специалистов по вопросам лабораторной диагностики и эпидемиологическому надзору за холерой осуществляется по программе, разработанной совместно специалистами всех противочумных институтов и утвержденной их руководителями. В рамках образователь- 
ных циклов профессиональной переподготовки по специальностям «Бактериология», «Эпидемиология», «Лабораторное дело» предусмотрен модуль, посвященный холере, в объеме от 6 до 72 ч.

В настоящее время на территории РФ функционируют 14 противочумных станций (ПЧС), не все из них имеют лицензию на образовательную деятельность. Поэтому подготовку специалистов по работе с ПБА I-II групп патогенности ведут и Центры гигиены и эпидемиологии в виде семинаров продолжительностью от 2 до 30 ч, оказывая консультативно-методическую помощь практическому здравоохранению в соответствии с уставом организации, с последующей выдачей справки или свидетельства об обучении. С одной стороны, такая практика позволяет обучить большее количество специалистов Роспотребнадзора и М0, но уровень подготовки, особенно при проведении коротких семинаров, по-видимому, недостаточен для полноценного повышения квалификации. Кроме того, зачастую нет заявленной программы цикла обучения, соответственно нет стандартного подхода к проведению учебных занятий.

Для оценки уровня подготовки специалистов по вопросам лабораторной диагностики и эпидемиологическому надзору за холерой было проведено анкетирование сотрудников филиалов ФБУЗ «Центр гигиены и эпидемиологии в Ростовской области». При анализе полученных анкет установлено, что повышение квалификации по холере прошли $65 \%$ бактериологов и 28\% биологов. Среди эпидемиологов практически нет специалистов, прошедших подготовку по вопросам эпидемиологического надзора за холерой [6]. Велика вероятность того, что аналогичная ситуация складывается и в других областях и регионах. В связи с этим необходимы стандартизация и введение единообразия методологических подходов при подготовке специалистов по холере в различных организациях.

На базе ФКУЗ «Ростовский-на-Дону противочумный институт» Роспотребнадзора ежегодно перед началом эпидсезона проводится обучение по дополнительной профессиональной программе повышения квалификации «Лабораторная диагностика и эпидемиологический надзор за холерой» объемом 78 ч, утвержденной руководителями всех противочумных институтов РФ в 2013 г. и актуализированной сотрудниками института в 2017 г. Целью обучения по данной программе является получение теоретических и практических знаний по микробиологии, эпидемиологии, клинической картине холеры, организации лабораторных исследований, алгоритмам и методам лабораторной диагностики возбудителей холеры и холерных вибрионов не 01/не 0139 серогрупп, других патогенных вибрионов. Категория слушателей - врачи-бактериологи и врачи-эпидемиологи учреждений Роспотребнадзора и учреждений других министерств и ведомств, участвующих в осуществлении эпидемиологического надзора за холерой. Программа включает изучение теоретических вопросов: соблюдение требований сани тарно-эпидемиологических правил и безопасности работы с микроорганизмами I-II групп патогенности, микробиологии, лабораторной диагностики, серологических и молекулярно-биологических методов исследования, клинических проявлений, патогенеза, иммунитета и вакцинопрофилак- тики при холере, контроля питательных сред для выделения и культивирования возбудителя холеры, эпидемиологии, эпидемиологического надзора и организации противохолерных мероприятий.

С момента разработки первой программы по холере обучение проводили в очной форме, что предусматривало личное присутствие преподавателя и слушателей на занятиях и реализовывалось на территории образовательной организации. Однако это требовало достаточно длительного отрыва от работы и ограничивало возможности обучения специалистов. Конечно, была возможность проведения подготовки на базе учреждения, чьи сотрудники осваивали программу, однако выездные циклы требовали определенных условий для проведения занятий, особенно по 00И, в связи с чем выездные очные циклы не нашли широкого распространения.

Позднее часть теоретического материала была выделена для самостоятельного ознакомления специалистов по рекомендованным источникам литературы и нормативно-методическим документам, предоставленным образовательным учреждением. Обучение стало очно-заочным и включает 3 фазы: на первой слушателей знакомили с программой и предоставляли им материалы для самостоятельного освоения. На второй фазе проводили очные теоретические и практические занятия. Третья фаза - итоговая проверка знаний в виде квалификационного экзамена или теста. Используемая в настоящее время очно-заочная программа повышения квалификации является наиболее оптимальной формой подготовки практических специалистов для работы с возбудителем холеры.

Большое внимание как при очной, так и при очно-заочной форме реализации программы уделено практическим занятиям, направленным на актуализацию знаний, умений и навыков безопасного выполнения манипуляций с ПБА, решение бактериологических задач с культурами холерных вибрионов в условиях, максимально приближенных к реальной лабораторной диагностике холеры, что делает образовательный процесс более наглядным и эффективным.

Актуальной тенденцией является поддержание профессионального уровня и приобретение новых компетенций, соответствующих современным требованиям в изменяющихся условиях, что обусловливает необходимость регулярного пополнения багажа профессиональных знаний на протяжении всей жизни. В связи с этим одной из основных задач модернизации отечественного здравоохранения является подготовка медицинских кадров на основе непрерывного медицинского образования (НMO), что обеспечивает постоянное повышение квалификации и рост профессионализма специалистов высшего и среднего медицинского звена по программам дополнительного профессионального образования.

И если ранее обучение по образовательным программам повышения квалификации проводили 1 раз в 5 лет, то современные нормы предусматривают уменьшение временного диапазона - 1 раз в год. С целью непрерывного совершенствования профессиональных навыков и расширения квалификации, а также для обеспечения допуска к периодической аккредитации специалистам необходимо обучение с общим 
минимальным суммарным объемом различных компонентов непрерывного образования не менее 250 зачетных единиц трудоемкости (3ЕT) за 5-летний период с ежегодным обучением в объеме около 50 ЗЕТ. Рекомендуемый ежегодный объем освоения программ повышения квалификации 36 3ЕТ, суммарный объем обучения на очных образовательных мероприятиях и освоения интерактивных образовательных модулей - 14 3ЕТ [7]. В связи с этим возникла необходимость в более коротких образовательных программах объемом 36 ч. В 2019 г. в ФКУЗ «Ростовский-на-Дону противочумный институт» Роспотребнадзора разработана дополнительная профессиональная образовательная программа повышения квалификации «Лабораторная диагностика и эпидемиологический надзор за холерой» объемом 36 ч.

Разработка новых программ предусматривает и внедрение современных подходов к обучению с акцентом на повышение квалификации непосредственно на рабочем месте с использованием информационно-компьютерных ресурсов и дистанционных технологий, поскольку динамично изменяющиеся экономические условия характеризуются высокой мобильностью работающего населения [8-11].

В рамках Концепции научного обеспечения деятельности органов и организаций Федеральной службы по надзору в сфере защиты прав потребителей и благополучия человека до 2020 г., утвержденной приказом Роспотребнадзора от 23.12.2015 № 1355, а также в соответствии с Федеральным законом от 01.09.2013 № 273 ст.16 «0б образовании в Российской Федерации» и приказом Минобрнауки России от 01.07.2013 № 499 «0б утверждении Порядка организации и осуществления образовательной деятельности по дополнительным профессиональным программам» развитие дистанционного обучения признано одним из ключевых направлений $[12,13]$, поскольку имеет дополнительные преимущества: работающим специалистам сложно освободить время для длительного обучения; слушатели имеют повышенную мотивацию к обучению и не требуют проведения «контрольно-принудительных» операций как в процессе обучения, так и при осуществлении контроля; для взрослых слушателей исключается «психологически-воспитательный» компонент, их в основном интересует профессиональнопознавательная часть обучения и получение соответствующих компетенций выходит на первый план по сравнению с необходимостью получения документа об образовании.

Однако для реализации образовательных программ с применением электронного обучения, дистанционных образовательных технологий в образовательной организации должны быть созданы условия для функционирования электронной информационно-образовательной среды, включающей электронные информационные и образовательные ресурсы, совокупность информационных и телекоммуникационных технологий, соответствующих технологических средств, обеспечивающих освоение обучающимися образовательных программ, независимо от их места нахождения $[14,15]$.

Во ФКУЗ «Ростовский-на-Дону противочумный институт» Роспотребнадзора разработан образовательный портал на основе системы eFront, расположенный на сайте http://dist. antiplague.ru, в том числе его мобильная версия, позволяю- щая работать на современных гаджетах в любое удобное для обучающегося время. Каждый раздел на портале доступен для просмотра в режиме реального времени и сопровождается промежуточной аттестацией в разработанной системе тестирования, позволяющей оценить степень освоения знаний, что направлено на повышение эффективности обучения и позволяет специалисту затрачивать на образовательный процесс с отрывом от работы минимальное количество времени с максимальным освоением материала [16]. При организации дистанционного обучения акцент ставится на создании и обеспечении слушателей учебными, учебнометодическими материалами, различного рода средствами обучения, что увеличивает значимость стандартизации методологических подходов к составлению электронных учебно-методических комплексов и методов контроля.

При этом, несмотря на широкое внедрение дистанционных образовательных технологий, из педагогического процесса нельзя полностью исключать очную форму обучения, поскольку проведение практических занятий, обеспечивающих совершенствование навыков биологической безопасности при работе с 00M, к которым относится и холера, осуществимо только при непосредственном контакте и контроле со стороны преподавателя, что делает невозможным полностью дистанционное обучение.

Однако не все специалисты могут пройти полноценное повышение квалификации даже в такой сокращенной форме (36 4). Поэтому для оперативного приобретения знаний и соответствующих навыков, ознакомления с актуальными тонкостями работы для квалифицированного персонала возможно проведение краткосрочных семинаров и тренингов.

Семинар - это одна из форм проведения обучающих занятий, основными принципами которых являются обмен опытом и обсуждение, необходимое для закрепления пройденного теоретического материала. Краткосрочные семинары - это программы продолжительностью менее 16 ч, не предусматривающие проведение итоговой аттестации [17]. Семинары могут быть открытыми, их посещают все заинтересованные участники, и корпоративными - доступными лишь для работников конкретной организации.

Семинары принято делить на 3 категории: обучающие (состоящие только из теоретической части, практикуются в образовательных учреждениях), научно-практические (для научных работников, имеющих опыт и знания, знакомых с работами коллег в рассматриваемой теме и активно участвующих в обсуждении); бизнес-семинары (обмен опытом среди представителей одной специальности, усовершенствование знаний по новым методикам работы считаются лучшим методом повышения квалификации). В отдельную категорию можно вынести также вебинары, проводимые в режиме онлайн, когда лектор перед веб-камерой излагает теоретическую часть семинара, а участники слушают доклад и смотрят презентацию за своими компьютерами.

Цель проведения семинара заключается в получении знаний (профильные занятия являются необходимой составляющей для профессионального роста в той или иной сфере деятельности), обмене опытом (присутствие на семинарах позволяет участникам обмениваться опытом и получать ответы на интересующие вопросы по теме от более опытных 
людей), общении, поскольку посещение семинаров позволяет обзавестись полезными знакомствами для потенциального сотрудничества и расширения сферы взаимодействия организаций и учреждений разных ведомств.

Учитывая вышеизложенное, актуальной является разработка программ семинаров по холере с учетом требований к профессиональной компетенции в зависимости от функциональных обязанностей, выполняемых слушателями циклов объемом 6-8 ч и возможностью проведения на базе не только образовательного учреждения, но и других организаций. Семинар должен проходить таким образом, чтобы вся представляемая в процессе обучения информация закреплялась при реализации практической части (например, при демонстрации применения средств индивидуальной защиты различных типов; отборе, упаковке и транспортировке материала для исследования; решении ситуационных задач с обсуждением алгоритма действия специалистов в соответствии с функциональными обязанностями и т.д.).

\section{Зак^ючение}

Таким образом, оценка развития системы подготовки специалистов на территории РФ по вопросам лабораторной диагностики и эпидемиологическому надзору за холерой показало необходимость внедрения новых форм обучения и обеспечения способности реагировать на потребности слушателей, осуществлять учебный процесс с использованием современных информационно-коммуникационных технологий, позволяющих работающим специалистам без отрыва от производственной деятельности и в достаточно короткие сроки повысить свою квалификацию.

\section{CВEАЕНИЯ ОБ АВТОРАХ}

ФКУЗ Ростовский-на-Дону противочумный институт Роспотребнадзора, Ростов-на-Дону, Российская Федерация:

Сизова Юлия Владимировна (Yulia V. Sizova) - кандидат биологических наук, старший научный сотрудник отдела профессиональной переподготовки и повышения квалификации специалистов

E-mail: yuisa@mail.ru

https://orcid.org/0000-0002-7831-7767

Бурлакова Ольга Спартаковна (Olga S. Burlakova) - кандидат медицинских наук, ведущий научный сотрудник, исполняющий обязанности начальника отдела профессиональной переподготовки и повышения квалификации специалистов

E-mail: burlakova_os@antiplague.ru

https://orcid.org/0000-0002-0553-0866

Люкшина Елена Юрьевна (Elena Yu. Lyukshina) - кандидат медицинских наук, старший научный сотрудник отдела профессиональной переподготовки и повышения квалификации специалистов

E-mail: e-lyu_7@rambler.ru

https://orcid.org/0000-0002-4571-7756

Сокольская Ольга Александровна (Olga A. Sokol'skaya) - младший научный сотрудник отдела профессиональной переподготовки и повышения квалификации специалистов

E-mail: olgasokolsckaya@yandex.ru

https://orcid.org/0000-0003-3204-0077

\section{ヘИТЕРАТУРА}

1. Москвитина Э.А., Тюленева Е.Г., Кругликов В.А. и Ар. Холера: оценка эпиАемиологической обстановки в мире и России в 2008 2017 гг. прогноз на 2018 г. // Проблемы особо опасных инфекций. 2018. Вып. 1. С. 36-43. 536.

2. WHO. Cholera // Wkly Epidemiol. Rec. 2017. Vol. 92, N 36. P. 521

3. Oyugi E.O., Boru1 W., Obonyo M. et al. An outbreak of cholera in western Kenya, 2015: a case control study // Pan Afr. Med. J. 2017. Vol. 28, suppl. 1. P. 12.

4. Ryan S.J., Stewart-Ibarra A.M., Ordóñez-Enireb E. et al. Spatiotemporal variation in environmental Vibrio cholerae in an Estuary in Southern Coastal Ecuador // Int. J. Environ. Res. Public Health. 2018. Vol. 15, N 3. P. 486.

5. Безопасность работы с микроорганизмами I-ІІ групп патогенности (опасности): СП 1.3.3118-13 // Бюмюютень нормативных и метоАических Аокументов ГоссанэпиднаАзора. 2013. № 3 (13). С. 95-115.

6. Сизова Ю.В., Бурлакова О.С., ^юкшина Е.Ю. и Ар. Анализ результатов мониторинга кадрового состава и уровня подготовки специалистов Роспотребнадзора Ростовской области // Материалы научно-практической конференции “Актуальные вопросы изучения особо опасных и природно-очаговых болезней”. Ростов-на-Аону, 2019. С. 472 479.
7. URL: http://edu.rosminzdrav.ru/specialistam/vo/\#c543 (Аата обращения: 25.02.2020)

8. Амиреев С.А., Ибраева Г.А. Оценка профессионализма врачейэпиАемиологов посреАством тест-системы контроля знаний // Материалы VIII Всероссийского съезда эпидемиологов, микробиологов и паразитологов. Москва, 2002. Т. 4. С. 131-132.

9. Филиппов А.А. Подготовка специалистов по особо опасным инфекциям // Материалы VIII Всероссийского съезАа эпидемиологов, микробиологов и паразитологов. Москва, 2002. Т. 4. С. 143-144.

10. Матущенко Е.В., Кумпан А.В., Рудаков Н.В. Анализ и перспективы развития Аистанционных технологий в послеАипломном образовании врачей бактериологов // Национальные приоритеты России. 2016. № 4 (22). С. 152-155.

11. Муслимов В.В. Цифровое зАравоохранение - как фактор рево^юционных преобразований в отрасли // Современные проблемы заравоохранения и медицинской статистики. 2018. № 3. С. 63-74.

12. Концепция научного обеспечения деятельности органов и организаций Фелеральной службы по наАзору в сфере защиты прав потребителей и благополучия человека до 2020 года: Приказ Роспотребнадзора от 23 Аекабря 2015 года № 1355.

13. Об утверждении Порядка организации и осуществления образовательной деятельности по Аополнительным профессиональным программам: 
Приказ Министерства образования и науки Российской ФеАерации от 1 июля 2013 года № 499 (с изменениями на 15 ноября 2013 года).

14. Об образовании в Российской Федерации: Федеральный Закон № 273-Ф3 от 01.09.2013 г.

15. Методические рекомендации по реализации дополнительных профессиональных программ с использованием Аистанционных образовательных технологий, электронного обучения и в сетевой форме (Письмо Министерства образования и науки РФ от 21 апреля 2015 г. № BK-1013/06).
16. Сизова Ю.В., Бурлакова О.С., Водопьянов А.С. и Ар. Возможность использования Аистанционных технологий при подготовке специалистов по особо опасным инфекциям // Здоровье населения и среда обитания. 2017. № 7. С. 11-17.

17. Разъяснения об особенностях законодательного и нормативного правового обеспечения в сфере Аополнительного профессионального образования: Письмо Министерства образования и науки Российской Федерации от 7 мая 2014 г. № AK-1261/06.

\section{REFERENCES}

1. Moskvitina E.A., Tyuleneva E.G., Kruglikov V.D., et al. Cholera: Assessment of Epidemiological Situation on Cholera around the World and in Russia in 2008-2017. Forecast for 2018. Problemy osobo opasnykh infektsiy [Problems of Particularly Dangerous Infections]. 2018; (1): 36-43. (in Russian)

2. WHO. Cholera. Wkly Epidemiol Rec. 2017; 92 (36): 521-36.

3. Oyugi E.O., Boru1 W., Obonyo M., et al. An outbreak of cholera in western Kenya, 2015: a case control study. Pan Afr Med J. 2017; 28 (suppl 1): 12.

4. Ryan S.J., Stewart-Ibarra A.M., Ordóñez-Enireb E., et al. Spatiotemporal variation in environmental Vibrio cholerae in an Estuary in Southern Coastal Ecuador. Int J Environ Res Public Health. 2018; 15 (3): 486.

5. Safety of work with microorganisms of I-II groups of pathogenicity (hazard): SP 1.3.3118-13. Byulleten' normativnykh i metodicheskikh dokumentov Gossanepidnadzora [Bulletin of Normative and Methodical Documents of Gossanepidnadzor]. 2013; 3 (13): 95-115. (in Russian)

6. Sizova Yu.V., Burlakova O.S., Lyukshina E.Yu., et al. Analysis of the results of monitoring the personnel and the level of training of spe cialists of Rospotrebnadzor of the Rostov Region. In: Materialy nauchnoprakticheskoy konferentsii "Aktual'nye voprosy izucheniya osobo opasnykh i prirodno-ochagovykh bolezney" [Materials of the scientific and practical conference "Topical Issues of Studying Especially Dangerous and Natural Focal Diseases"]. Rostov-on-Don, 2019: 472-9. (in Russian)

7. URL: http://edu.rosminzdrav.ru/specialistam/vo/\#c543 (date of access February 25, 2020)

8. Amireev S.A., Ibraeva G.A. Assessment of the professionalism of doctors-epidemiologists by means of a knowledge control test. In: Materials of the VIII all-Russian Congress of Epidemiologists, Microbiologists and Parasitologists. Moscow, 2002; (4): 131-2. (in Russian)

9. Filippov A.A. Training of specialists in especially dangerous infections. In: Materials of the VIII all-Russian Congress of Epidemiologists,
Microbiologists and Parasitologists. Moscow, 2002; (4): 143-4. (in Russian)

10. Matushchenko E.V., Kumpan L.V., Rudakov N.V. Analysis and prospects of the remote technology development in postgraduate education of bacteriologists. Natsional'nye prioretety Rossii [National Priorities of Russia]. 2016; 4 (22): 152-5. (in Russian)

11. Muslimov V.V. Digital health as a factor of revolutionary changes in the public health. Sovremennye problemy zdravookhraneniya i meditsinskoy statistiki [Modern Problems of Healthcare and Medical Statistics] 2018; (3): 63-74. (in Russian)

12. The Concept of scientific support for the activities of bodies and organizations of the Federal Service for Supervision of Consumer Rights Protection and Human Welfare until 2020: Order of Rospotrebnadzor from December 23, 2015 No. 1355. (in Russian)

13. On approval of the Procedure for organizing and carrying out educational activities for additional professional programs: Order of the Ministry of Education and Science of the Russian Federation dated July 1, 2013 No. 499 (as amended on November 15, 2013). . (in Russian)

14. On education in the Russian Federation: Federal Law No. 273-FZ from 01.09.2013. (in Russian)

15. 15. Guidelines for the implementation of additional professional programs using distance learning technologies, e-learning and online (Letter of the Ministry of Education and Science of the Russian Federation of April 21, 2015 No. VK-1013/06). (in Russian)

16. Sizova Yu.V., Burlakova O.S., Vodop'yanov A.S., et al. Possibility of use of distance technologies in training on especially dangerous infections. Zdorov'e naseleniya i sreda obitaniya [Public Health and Life Environment]. 2017; (7): 11-7. (in Russian)

17. Clarifications on the specifics of legislative and regulatory legal support in the field of continuing professional education: Letter of the Ministry of Education and Science of the Russian Federation dated May 7 , 2014 No. AK-1261/06. (in Russian) 